\section{A line of classical physiology}

\section{P.D. Wall}

The Senses.

Edited by H.B. Barlow and

J.D. Mollon.

Cambridge University Press: 1982.

Pp.490. Hbk £30, \$59.50;

pbk £12.50, \$19.95.

THE Senses has been written for undergraduate courses for medical students and others concerned with the topic. Some 60 per cent of it is reasonably devoted to the visual system, with a further 20 per cent on the auditory system. The remainder covers the vestibular system, the cutaneous senses, and smell and taste. Each chapter has a brief bibliography of suggestions for further reading, including general reviews and special references.

Many senior teachers of physiology will find this book satisfying, classical and central. More junior research workers may find it puzzling, eccentric and parochial. For example, a paper is recommended with "read this if you have only a little time to prepare for a tutorial essay"; and an old book which missed the point even in its day is "by an intellectual for intellectuals". In addition there are some curious inconsistencies, such as the chapter on neuroanatomy of vision which makes no reference to the multiple visual pathways alluded to later in the book. The chapter on skin nudges into the 1970 s with an attitude unchanged from the 1870 s.

A reader of this year's proceedings of the American Neuroscience Society would have difficulty in many areas if he were to search The Senses for the background to the issues which today enthrall the research worker. That, however, might be an unfair test for a book which intentionally succeeds in presenting clearly a particular line of classical physiology.

P.D. Wall is a Professor in the Department of Anatomy at University College London.

\section{Two-faced toxicology}

\section{T.A. Connors}

Principles and Methods of Toxicology.

Edited by A. Wallace Hayes.

Raven: 1982. Pp.750. \$84.32.

Principles of Biochemical

Toxicology.

By John A. Timbrell.

Taylor and Francis/J.K. Burgess Inc.:

1982. Pp.245. £13.50, \$28.50.

UNLIKE research into, say, oncogenes or recombinant DNA technology, toxicology is not popularly thought of as a glamorous subject. Nevertheless, it is arguable that toxicology is one of the most important areas of medical research since the causes of many serious human diseases are not known and most may eventually be proven to be due to "environmental" and hence preventable factors. A further problem for the student is that the subject may seem to be rather ill-defined: the scientist investigating the impact of pesticides on flora and fauna, the clinician studying the effects of drug abuse and the industrialist evaluating the safety of a novel chemical can all rightly call themselves toxicologists. So it comes as no surprise to find that the two volumes reviewed here are quite different, even though they both have the word "toxicology" in their titles.

As is made clear in the preface, the authors in Principles and Methods of Toxicology do not attempt to go in great detail into the mechanisms by which chemicals cause specific damage to biological tissues, but rather deal with the methods used to determine whether or not a chemical is likely to be hazardous to human beings. This corner of toxicology nevertheless covers a very large area, but here it is coped with very successfully and lucidly. Successive chapters deal with acute and chronic (including carcinogenicity) testing and with more specialized techniques such as inhalation toxicity and skin and eye testing. Detailed accounts are given of the methods used to detect specific toxicity in all major organs of the body. Toxicity to the fetus is also considered as well as newer aspects of toxicology such as behavioural and immunotoxicology. The book concludes with a chapter on pharmacokinetics and, importantly, with a discussion of the knotty problem of extrapolation to man.

All in all I found this an excellent book and would endorse the editor's words in saying that the volume will be of particular value to students and others who have not yet entered a specialized field of toxicology. Indeed I would go further, and suggest that scientists involved in safety evaluation - especially those in government who are responsible for aspects of the regulation of chemicals will also find it useful.

As suggested by the title, Timbrell's book is the other side of the coin and deals particularly with the biochemical basis of toxicology. However, again because of the complexity of the subject, no attempt is made to review all that is known about biochemical mechanisms. The book reflects the author's own interests and concentrates on the principles of

\section{Gardner in Britain}

Next week Oxford University Press will publish a paperback edition of Martin Gardner's Science: Good, Bad and Bogus, the first time the book has been available in Britain. For review see Nature 295, 351 (1982). Price of the new edition is $£ 4.95$. pharmacokinetics, drug disposition and metabolism, although there are also concise but interesting accounts of the types of toxic response to foreign chemicals and of mechanisms of selective toxicity to specific tissues.

I do have a small criticism of this book. Some important areas of toxicology, for example heavy metals, are dealt with so briefly as to imply either that they are unimportant or that little is known about them. To state, for example, that little is known about the relationship between inhibition of acetylcholinesterase and delayed neurotoxicity is to ignore the excellent work done in this field on mechanisms (although to be fair a reference to one of the many reviews in this area is included in the bibliography). I would also take issue with the assertion on p.127 that cancer induction is an irreversible change. Enough is already known about repair mechanisms, transforming growth factors and the reversibility of promotors to hold out some hope that when we know more about the complex process of cancer induction some cancers will prove to be reversible.

Nevertheless the major sections of the book are excellent, explaining biochemical mechanisms clearly and succinctly, with many first-class diagrams and figures. Principles of Biochemical Toxicology is certainly to be recommended, especially to its intended readership of undergraduate students.

T.A. Connors is Director of the MRC Toxicology Unit, Carshalton, Surrey.

\section{There is no "why?"}

\section{Stuart Sutherland}

\section{Visual Information Processing.}

By Kathryn T. Spoehr and Stephen

W. Lehmkuhle.

W.H. Freeman: 1982. Pp.298.

Hbk \$21.95, £17.80; pbk £10.40.

THE cant phrase "information processing theory", despite its savour of novelty and precision, means no more than the attempt to specify the mechanisms underlying the performance of some task; with the exception of the extreme behaviourists and a few cranks like J. J. Gibson, all experimental psychologists since about the beginning of the century have pursued this approach. It is neither novel nor is it characterized by precision. Information processing theorists do not aspire to the rigour of working computer programs, they are content with flow-charts which often contain boxes with labels such as "Recognition" and which are more a means of concealing our ignorance than dissipating it.

One would expect anyone bent on pursuing an information processing approach 